\title{
APLIKASI AGEN CERDAS UNTUK PEMBELAJARAN PEMPROGRAMAN BERORIENTASI OBJEK BERBASIS NATURAL LANGUAGE PROCESSING (NLP)
}

\author{
Khairil Anam,S.Kom,M.Kom ${ }^{1}$, Sehman,S.Kom,M.Kom ${ }^{2}$ \\ Universitas Maarif Hasyim Latif ${ }^{1}$, Universitas Maarif Hasyim Latif ${ }^{2}$ \\ e-mail:khairil_anam@dosen.umaha.ac.id,sehman@dosen.umaha.ac.id
}

\begin{abstract}
The existence of a touch of technology on laboratory learning becomes another alternative as a supporter of laboratory learning. Different practitioner's wishes and intensity of relatively short laboratory practice which resulted in dissatisfaction in the implementation of a practicum. Thus, an intelligent learning alternative is needed. This intelligent learning aims to provide high-quality and high-performance training skills that can assist the practitioner in solving problems related to practicum materials. The intelligent learning system is a learning system that handles some student instruction without any intervention from a teacher.

Alternative learning system that can support the creation of Intelligent Learning System is by Natural Language Processing (NLP) method. This final project provides an explanation of the creation and implementation of intelligent learning systems in the Object Oriented Programming Computer Laboratory. This system consists of several stages: parsing, similarity, stemming, Knowledge Base which is designed in an interactive form between praktikan and agent based dialoge based application. The success rate of this system in answering questions from praktikan session II is $88.75 \%$.
\end{abstract}

Kata kunci: Intelligent Learning System, Natural Language Processing (NLP), Parsing, Similarity, Stemming, Knowledge Base

\begin{abstract}
ABSTRAK
Adanya sentuhan teknologi pada pembelajaran laboratorium menjadi alternatif lain sebagai penunjang pembelajaran Laboratorium. Keinginan praktikan yang berbeda-beda dan intensitas pelaksanaan praktikum yang relatif sebentar yang berakibat ketidakpuasan dalam pelaksanaan sebuah praktikum. Dengan demikian, diperlukan sebuah alternatif pembelajaran cerdas. Pembelajaran cerdas ini bertujuan untuk memberikan keterampilan pelatihan yang berkualitas tinggi dan kinerja tinggi yang dapat membantu praktikan dalam memecahkan permasalahannya terkait dengan materi praktikum. Sistem Pembelajaran cerdas merupakan sistem pembelajaran yang menangani beberapa instruksi pelajar tanpa adanya intervensi dari seorang guru.

Alternatif sistem pembelajaran yang dapat mendukung terciptanya Intelligent Learning System adalah dengan metode Natural Language Processing (NLP). Penelitian ini memberikan penjelasan tentang pembuatan dan implementasi sistem pembelajaran cerdas pada Laboratorium Komputer Pemrograman Berorientasi Object. Sistem ini terdiri dari beberapa tahapan yaitu parsing, similarity, stemming, Knowledge Base yang dirancang dalam bentuk interaktif antara praktikan dan agen berbasis dialoge based application. Tingkat keberhasilan dari sistem ini dalam menjawab pertanyaan dari praktikan sesi II adalah $88.75 \%$.
\end{abstract}

Kata kunci: Sistem Pembelajaran Cerdas, Natural Language Processing (NLP), Parsing, Similarity, Stemming, Basis Pengetahuan 


\section{PENDAHULUAN}

Perkembangan ilmu pengetahuan dan teknologi telah meningkatkan taraf hidup dan kemudahan aktivitas manusia dalam berbagai aspek kehidupan. Salah satu dampak teknologi yang paling dirasakan saat ini adalah dalam bidang informasi dan pendidikan, termasuk di dalamnya sistem pembelajaran dan kegiatan belajar mengajarnya. Pada zaman modern sekarang ini masalah pendidikan merupakan suatu hal yang sangat penting.

Pembelajaran cerdas ini bertujuan untuk memberikan keterampilan pelatihan yang berkualitas tinggi dan kinerja tinggi pada semua tingkat pendidikan melalui dukungan teknologi yang disediakan dengan semua alat dan sumber daya yang bertujuan untuk mencapai keunggulan dalam proses pembelajaran. Alternatif sistem pembelajaran yang dapat mendukung terciptanya Intelligent Learning System adalah dengan metode Natural Language Processing (NLP). Pemrosesan bahasa alami sering dianggap sebagai cabang untuk sistem pembelajaran cerdas, sehingga dengan adanya sistem ini dapat memberikan pengajaran secara private yang diharapkan dapat membantu proses pembelajaran di laboratorium.

Rancangan sistem dalam penelitian ini meliputi penjelasan tentang semantik yang melibatkan berbagai teknik antara lain Linguistic Analysis (Parsing), Grammar (steamer), pencocokan pertanyaan dengan basis pengetahuan agen (Knowledge Base).

\subsection{Semantik}

Proses semantik di dalam penelitian ini merupakan proses penyusunan kalimat pertanyaan praktikan berdasarkan relasi, deskripsi, dan obyek sesuai dengan basis pengetahuan.

\subsection{Parsing}

Parsing dalam penelitian ini adalah proses untuk mengurai dan memecah kalimat menjadi bentuk kata-kata dan frasa-frasa. Parsing adalah Suatu sistem yang mengambil kalimat input bahasa alami dan menguraikannya ke dalam beberapa bagian gramatikal (kata benda, kata kerja, kata sifat, dan lain-lain).

Berikut ini adalah flowchart dari penggunaan parsing :

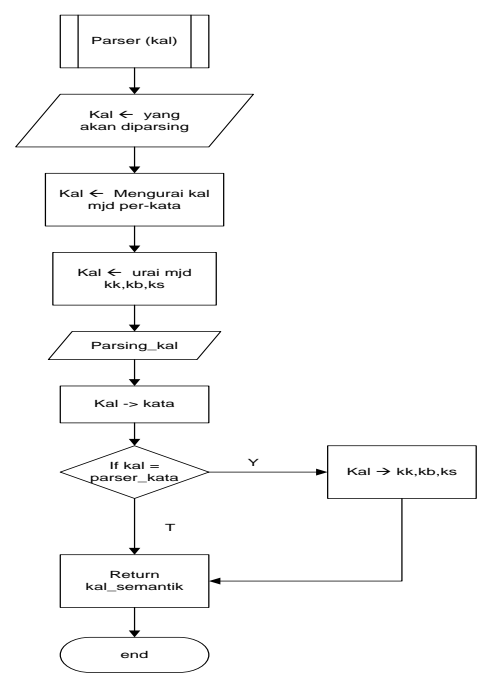

Gambar 1. Flowchart Parsing

\subsection{Stemming}

Stemming dalam penelitan ini adalah proses pemetaan dan penguraian berbagai bentuk (variants) dari suatu kalimat yang diinputkan oleh praktikan menjadi bentuk kata dasarnya. Contoh stemming antara lain "pewarisan" dikonstruksi dari awalan "pe"+ dan akhiran "an", 
awalan "pe" dan akhiran "an" dihilangkan sehingga hasil stemming yang diharapkan adalah kata dasar "waris". Setiono :

Berikut ini adalah flowchart dari penggunaan stemmer dengan alroritma Arifin dan

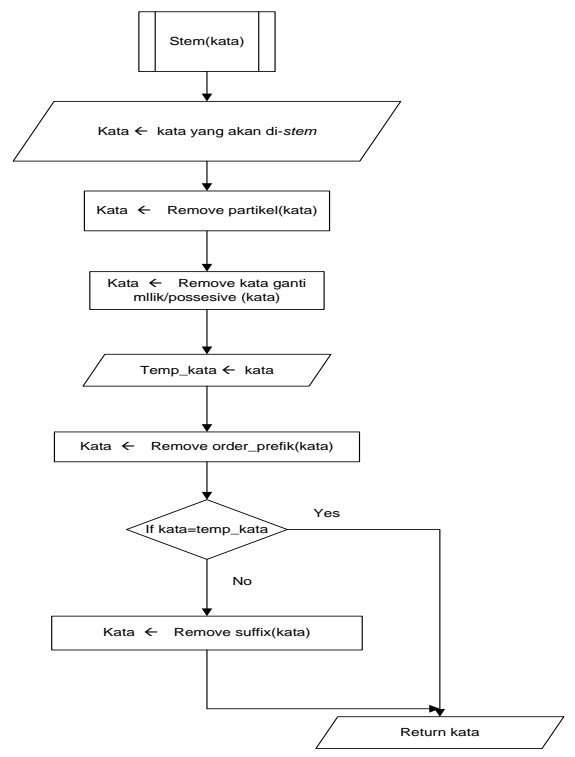

Gambar 2. Flowchart Stemming

\section{TINJAUAN PUSTAKA}

\subsection{Natural Language Processing (NLP)}

Natural Language Processing (NLP) atau Pemrosesan Bahasa Alami (PBA) adalah cabang dari sebuah ilmu komputer dan linguistik yang mengkaji interaksi antara komputer dengan bahasa (alami) manusia. Menurut Watson (2008: 137) pemrosesan bahasa alami sering dianggap sebagai cabang dari kecerdasan buatan dan bidangkajiannya bersinggungan dengan linguistik komputasional. Kajian pemrosesan bahasa alami antara lain mencakup segmentasi tuturan speech segmentation, segmentasi teks (text segmentation), penandaan kelas kata (part-of-speech tagging), serta pengawataksaan makna word sense disambiguation Meskipun kajian yang mencakup teks dan tuturan, (speech processing).

Menurut Suryanto (2002: 101-102) ada beberapa komponen dan tahapan dalam NLP, yaitu:

\section{a. Morphological Analysis}

Individual words dianalisis ke dalam komponen-komponennya, dan non-word tokens, seperti tanda baca, dipisahkan dari kata.

\section{Syntactic Analysis}

Dereten kata-kata ditransformasikan ke dalam struktur yang menunjukkan bagaimana katakata berhubungan antara satu dengan lainnya.

3. Semantic Analysis

Memberikan arti terhadap struktur-struktur yang dibangun oleh analyzer.

\section{Discourse Integration}

Arti dari suatu kalimat tunggal mungkin bergantung pada kalimat sebelumya dan mempengaruhi arti dari kalimat yang mengikutinya.

2.2 Agent 
Populernya penggunaan teknologi agen pada berbagai bidang ilmu bukan berarti membuat jelas definisi agen, tetapi justru membuat definisi agen semakin tidak jelas, karena setiap peneliti berusaha untuk mendefinisikan agen sesuai dengan latar belakang ilmu yang mereka miliki. Bagaimanapun juga sampai saat ini belum ada kesepakatan dari para peneliti tentang definisi dari agen. Kemudian didefinisikan oleh Romi Wahono [2001:5] sebagai berikut :

a. Agen mempunyai kemampuan untuk melakukan suatu tugas atau pekerjaan.

b. Agen melakukan suatu tugas/pekerjaan dalam kapasitas untuk sesuatu, atau untuk orang lain

\section{METODE}

Adapun tahapan-tahapan yang dilakukan didalam penelitian ini adalah sebagai berikut :

a) Perencanaan

Tahapan ini bertujuan untuk mempersiapkan langkah-langkah awal yang dibutuhkan dalam melakukan penelitian, mulai dari identifikasi masalah sampai pembuatan aplikasi. Pada tahapan ini juga dirumuskan model sistem yang akan dikembangkan menggunakan metode natural language processing.

b) Pengumpulan data/Informasi (Information Gathering)

Berfungsi untuk mengumpulkan data atau informasi terkait sistem yang akan dibuat di laboratorium pemprograman berorientasi object.

c) Analisis

Data yang telah didapatkan selanjutnya akan dianalisa untuk kebutuhan perancangan knowledge base dan variabel natural language processing.

d) Desain/Perancangan

Pada tahap ini dilakukan perancangan antar muka berupa desain input, proses dan output.

e) Konstruksi (Pembuatan Perangkat Lunak)

Yaitu tahap untuk membangun sistem berdasarkan desain yang telah dibuat. Pada tahap ini akan dibangun perangkat lunak menggunakan bahasa pemrograman PHP dengan My SQL.

f) Pengujian

Selanjutnya akan dilakukan pengujian dari aplikasi yang telah dibuat untuk mengetahui tingkat akurasi dan ketepatan informasi yang dihasilkan.

\section{HASIL DAN PEMBAHASAN}

\subsection{Uji Coba Program}

Uji coba ini bertjuan untuk mengoreksi kebenaran jawaban atas pertanyaan praktikan pada proses interaktif pembelajaran. Gambar 4.

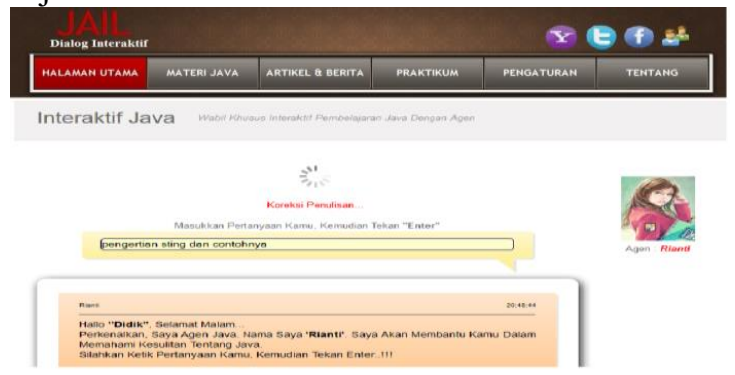

Gambar 4. Interaktif Praktikan dengan Agen

Gambar 5 merupakan hasil atau tanggapan dari agen terkait pertanyaan praktikan pada gambar 4 yang juga merupakan implementasi dari proses semantik natural language processing (NLP) dengan cara memasukkan pertanyaan pada textfield interaktif kemudian tekan enter (Gambar 4.) Setiap pertanyaan praktikan akan ditanggapi oleh agen melalui proses koreksi kata, semantik, dan translasi. Jika terjadi kesalahan penulisan kata akan ditampilkan pada history chat dan praktikan akan diberi pilihan Ya (setuju) atau Tidak (tidak setuju). 


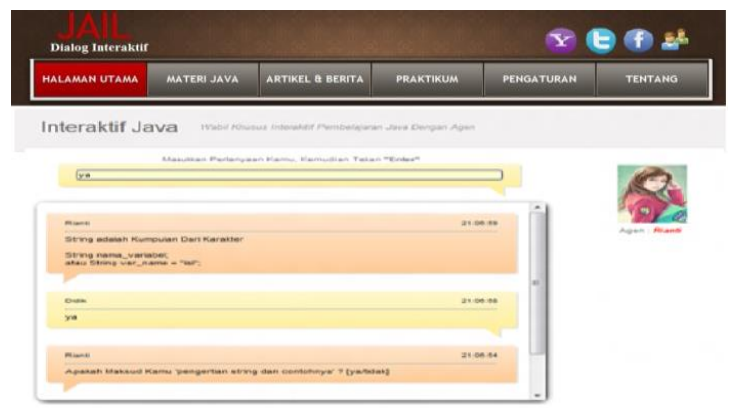

Gambar 5. Tanggapan Agen Java

\subsection{Hasil Uji Coba}

Hasil Uji keakuratan merupakan uji coba yang dilakukan oleh user yaitu adalah praktikan/mahasiswa Teknik Informatika yang mengambil matakuliah Praktikum Pemprograman Berorientsi Objek untuk menguji sistem.

Uji keakuratan yang diberikan kepada praktikan dilakukan untuk menguji sistem sebagai salah satu alternatif pembelajaran Laboratorium dengan sistem pembelajaran cerdas dan dengan menghadirkan virtual asdos (agen) sebagai pengajar. Uji coba sistem dilakukan dalam 1 (satu) sesi sebagaimana berikut ini :

1. Tahap Uji Coba Sistem (Sesi I) bertujuan untuk mengukur tingkat kesesuaian jawaban agen terhadap pertanyaan praktikan dalam bentuk interaksi dengan sistem yang dikembangkan.

Tabel 1. Transkrip Interaktif Praktikan 2 Sesi I

\begin{tabular}{|c|c|c|c|c|}
\hline No & NMM & Pertanyaan & Tanggapan & Releransi \\
\hline 1. & 06.2009 .1 .05192 & $\begin{array}{l}\text { arti string } \\
\text { bung }\end{array}$ & $\begin{array}{l}\text { S tring adalah kumpulan } \\
\text { dari karakter }\end{array}$ & Relevan \\
\hline 2. & 06.2009 .1 .05192 & $\begin{array}{l}\text { Cara } \\
\text { nulisnya }\end{array}$ & $\begin{array}{l}\text { S tring nama_variabel; } \\
\text { atau String var_name } \\
\text { "isi". }\end{array}$ & Relevan \\
\hline 3. & 06.2009 .1 .05192 & var 3va & $\begin{array}{l}\text { Kesalahan Penulisan } \\
\text { Variabel : 3va } \\
\text {-Variabel diawali angka : } \\
\text { Penulisan variabel yang } \\
\text { benar : va }\end{array}$ & Relevan \\
\hline 4. & 06.2009 .1 .05192 & $\begin{array}{l}5>6 \\
\text { maksudnya }\end{array}$ & $\begin{array}{l}\text { Operator > merupakan } \\
\text { jenis operator yang } \\
\text { berfungsi untuk } \\
\text { membandingkan varia bel. } \\
\text { Arti dari operator ini } \\
\text { adalah LEBIH BE SAR. } \\
\text { Hasil dari opera tor ini } \\
\text { adalah TRUE a tau } \\
\text { FAL SE. }\end{array}$ & $\begin{array}{l}\text { Tidak } \\
\text { Relevan }\end{array}$ \\
\hline 5. & 06.2009 .1 .05192 & $\begin{array}{l}\text { jela skan } \\
\text { contoh } \\
\text { string dan } \\
\text { bentuk } \\
\text { arraynya }\end{array}$ & $\begin{array}{l}\text { String nama_variabel; } \\
\text { ataus String var_name }= \\
\text { "isi"; } \\
\text { String a D; atau String a[] } \\
=\text { new String[4]: }\end{array}$ & Relevan \\
\hline 6. & 06.2009 .1 .05192 & $\begin{array}{l}\text { Jelaskaan } \\
\text { maksudnya } \\
\text { \&\&\& }\end{array}$ & $\begin{array}{l}\text { Operator \&\& merupakan } \\
\text { operator yang berart } \\
\text { AND dan berfiungsi unt } \\
\text { perbanding an antar } \\
\text { variabel. Hha ail dari } \\
\text { operasi ini TRUE atau } \\
\text { FAL SE. }\end{array}$ & Relevan \\
\hline 7. & 06.2009 .1 .05192 & $\begin{array}{l}\text { Bagaimana } \\
\text { sintax } \\
\text { fakrorial }\end{array}$ & 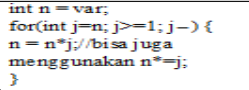 & Relevan \\
\hline 8. & 06.2009 .1 .05192 & $\begin{array}{l}\text { Kalau } \\
\text { alumya }\end{array}$ & $\begin{array}{l}\text { - Buat variabel } \mathrm{n}=\mathrm{var} \\
\text { - Lakukan perulangan } \mathrm{j} \\
\text { mulai dari nilai } \mathrm{n} \text { hingga } \\
1 . \\
\text { - Ganti nilai n dengan } \mathrm{n} \text { * } \\
\text { nilai j. } \\
\text { - Jika Perulangan Selesai, } \\
\text { Tampilkan Faktorial var. }\end{array}$ & Relevan \\
\hline \multicolumn{4}{|c|}{ Rata-rata Relevansi Tanggapan (\%) } & $\begin{array}{l}87,5 \% \\
\text { Relevan }\end{array}$ \\
\hline
\end{tabular}


Berdasarkan hasil uji coba dengan praktikan pada sesi I didapatkan Transkrip percakapan antara agen dalam sistem dan praktikan pada sesi I (Tabel 5) dapat disimpulkan bahwa agen dapat memberikan tanggapan relevan atas pertanyaan praktikan, pada sesi I sekitar sekitar 88,75\% tanggapan agen relevan.

Tabel 5. Rekapitulasi Uji Coba Sistem Sesi I

\begin{tabular}{|c|c|c|c|}
\hline NIM & $\begin{array}{c}\text { Jumlah } \\
\text { Pertanyaan }\end{array}$ & $\begin{array}{c}\text { Tanggapan } \\
\text { Relev an }\end{array}$ & $\begin{array}{c}\text { Tangapan } \\
\text { Tidak Relevan }\end{array}$ \\
\hline 06.2009 .1 .05045 & 10 & $90 \%$ & $10 \%$ \\
\hline 06.2009 .1 .05192 & 8 & $87,5 \%$ & $12,5 \%$ \\
\hline & Rata-Rata & $88,75 \%$ & $11,25 \%$ \\
\hline
\end{tabular}

\section{KESIMPULAN}

Setelah dilakukan implementasi dan uji coba sistem pada praktikan, maka penelitian ini dapat disimpulkan sebagai berikut :

1. Aplikasi pembelajaran cerdas ini diproses melalui beberapa beberapa tahapan metode dalam Natural Language Processing (NLP) yaitu parsing, stemming, semantik, dan translasi untuk memberikan jawaban dari pertanyaan para praktikan.

2. Proses semantik di dalam penelitian ini merupakan proses pengalihan bahasa alami ke dalam bahasa yang dimengerti oleh agen, yaitu dengan penyusunan kalimat pertanyaan praktikan berdasarkan relasi, deskripsi, dan obyek sesuai dengan basis pengetahuan agen.

3. Berdasarkan uji coba sistem didapatkan rata-rata Tanggapan relevan yang diberikan agen pada sesi I adalah $\mathbf{8 8 , 7 5 \%}$, sedangkan tanggapan tidak relevan yang diberikan agen pada sesi I menjadi 11,25\%.

Diharapkan aplikasi pembelajaran cerdas ini menjadi salah satu alternatif media pembelajaran untuk laboratorium bagi para praktikan untuk berdialog secara langsung dengan agen. Sistem ini juga diharapkan dapat membantu praktikan dalam memecahkan permasalahannya terkait dengan materi praktikum.

\section{DAFTAR PUSTAKA}

[1] Benny Hermawan (2004), Menguasai Java 2 \& Object Oriented Programing, Andi Yogyakarta

[2] Efrain Turban \& Jay E.Aronson (2005), Decision Support Systems and Inteligent System, Andi Yogyakarta

[3] Evgeniy Gabrilovich \& Shaul Markovitch (2009), Wikipedia-Based Semantic Interpretation for Natural Language Processing, 443-498

[4] Franklin \& Graesser (1996), A Taxonomy for Autonomous Agent, 23-35

[5] Luke Welling dan Laura Thomson (2001), PHP And My SQL Web Development, Sams Publishing

[6] Mark Watson (2008), Practical Artificial Intelligence Programming With Java, Creative Commons, United States

[7] Romi Satria Wahono (2001). Pengantar Software Agent Teori 4-21

[8] Suyanto (2011), Artificial Intelligence, Informatika, Bandung

[9] William J. Raynor, Jr. (1999), The International Dictionary of Artificial 